\title{
Ocular Adnexal Lymphoma pN3 TNM
}

\section{Finding v8}

National Cancer Institute

\section{Source}

National Cancer Institute. Ocular Adnexal Lymphoma pN3 TNM Finding v8. NCI

Thesaurus. Code C140877.

Ocular adnexal lymphoma with diffuse or disseminated involvement of peripheral and central lymph node regions. (from AJCC 8th Ed.) 